\title{
Searching for snakes: ball python hunting in southern Togo, West Africa
}

\author{
Neil D’Cruze ${ }^{1,2}$, Lauren A. Harrington², Délagnon Assou, ${ }^{3,4}$, Delphine Ronfot ${ }^{5}$, \\ David W. Macdonald ${ }^{2}$, Gabriel H. Segniagbeto ${ }^{3,4}$, Mark Auliya ${ }^{5,6}$
}

I World Animal Protection, 222 Grays Inn Rd., London WC1X 8HB, UK 2 Wildlife Conservation Research Unit, Department of Zoology, University of Oxford, Recanati-Kaplan Centre, Tubney House, Abingdon Road, Tubney, Abingdon OX13 5QL, UK 3 Laboratory of Ecology and Ecotoxicology, Department of Zoology and Animal Biology, Faculty of Sciences, University of Lomé, BP 1515, Lomé, Togo 4 Togolese Society for Nature Conservation (AGBO-ZEGUE NGO). 06 BP: 6057, Lomé, Togo 5 Zoological Research Museum Alexander Koenig, Department Herpetology, Adenauerallee 160, 53113, Bonn, Germany 6 Department of Conservation Biology, Helmholtz Centre for Environmental Research GmbH - UFZ, 04318, Leipzig, Germany

Corresponding author: Neil D’Cruze (neil.dcruze@zoo.ox.ac.uk)

Academic editor: E. Di Minin | Received 31 October 2019 | Accepted 28 February 2020 | Published 13 March 2020

http://zoobank.org/E239A308-5E74-4E8D-BF39-9690C1707A56

Citation: D’Cruze N, Harrington LA, Assou D, Ronfot D, Macdonald DW, Hoinsoudé Segniagbeto G, Auliya M (2020) Searching for snakes: ball python hunting in southern Togo, West Africa. Nature Conservation 38: 13-36. https:// doi.org/10.3897/natureconservation.38.47864

\begin{abstract}
The ball python (Python regius) is the single most exported live CITES-listed species from Africa, with a large proportion of snakes being sourced from Togo, West Africa, officially via a system reported nationally as "ranching". This study represents the first in-depth review of ball python hunting being carried out by rural communities in Togo for nearly 15 years. Our approach, focused at the bottom of the trade chain, permitted extensive detailed data to be collected from hunters, and provides a unique insight into the practices, drivers and impacts associated with this type of large-scale commercial wildlife trade activity. We show that ball python hunting remains an economically valuable endeavour for these rural hunters. However, it also highlights a number of potential legal, conservation and animal welfare issues associated with the current hunting practices being carried out in Togo (and neighbouring range States) to supply the snake farms and ultimately the international exotic pet trade. Our findings suggest that the methods applied on the ground do not accurately reflect those being reported to national authorities and international regulatory mechanisms such as CITES. This irregular, if not illegal, trade may also be unsustainable, as suggested by hunters reporting that there are fewer ball pythons in the wild than there were five years
\end{abstract}

Copyright Neil D'Cruze et al. This is an open access article distributed under the terms of the Creative Commons Attribution License (CC BY 4.0), which permits unrestricted use, distribution, and reproduction in any medium, provided the original author and source are credited. 
previously. We recommend that additional scientific investigation (focusing on the size and status of the wild population), better management, and enforcement of regulations, are required to ensure that ball python populations are managed in a sustainable, legal and traceable way.

\section{Keywords}

CITES, conservation, exotic pet, ranching, wildlife trade

\section{Introduction}

Snakes are hugely popular as exotic pets and consequently are traded alive globally in large numbers (e.g., Hoover 1998; Auliya 2003; Bush et al. 2014). Many are sourced from Africa and other tropical regions of the world (Bush et al. 2014; Jensen et al. 2018), where wildlife harvest and trade can play an important role in local livelihoods (e.g., Roe 2008). Increasingly, snakes, and other reptiles, are captive-bred for the pet trade both in source and destination countries (Brant 2001; Bush et al. 2014; Herrel and Meijden 2014). In some source countries, reptiles may also be produced via a process of "ranching", one definition being the "rearing in a controlled environment of animals taken as eggs or juveniles from the wild, where they would otherwise have had a very low probability of surviving to adulthood" (Convention on International Trade in Endangered Species of Wild Fauna and Flora [CITES] definition; Lyons et al. 2017).

In contrast to captive breeding or "wildlife farming", a topic that has received considerable attention in the scientific literature (see Tensen 2016 and references therein), ranching (as defined by CITES) is dependent on collection (hunting) of wild individuals. However, unlike wildlife farming, there have been relatively fewer studies, of which we are aware, of large-scale management operations that export live wild animals and their derivatives using the CITES source code "R", and their links with (and impacts on) wild populations, with the exception of those addressing crocodilian ranching (e.g., Jenkins et al. 2004). A species of particular interest in this regard is the ball python (Python regius), which is the single most exported live CITES-listed species from Africa (CITES Trade Database, https://trade.cites.org), the vast majority of which are exported as "ranched" specimens (source code R) (CITES Trade Database, https://trade.cites.org; see also Robinson et al. 2015).

In 2010, the ball python was evaluated as Least Concern on the IUCN Red List of Threatened Species (https://www.iucnredlist.org), but with high offtake levels and exploitation for the international pet trade (e.g., D'Cruze et al. 2020) cited as a main potential threat (Auliya and Schmitz 2010). According to the CITES trade database (https://trade.cites.org), over three million individual ball pythons have been exported from West Africa since the first recorded exports in 1982, with total annual exports from Range States averaging c.100,000 since 2007 (also see Robinson et al. 2015). More than $98 \%$ of ball python exports from Range States originate from Togo, Benin and Ghana, destined predominantly for consumers in the United States of America, Europe and Asia (CITES Trade Database, https://trade.cites.org; Robinson et al. 2015; Harrington et al., in prep.). 
The export of "ranched" specimens of ball pythons from West Africa can be traced back to a number of registered reptile "farms" operating in Benin, Ghana and Togo (de Buffrénil 1995). In Togo, most of these farms are based in, or less than, $10 \mathrm{~km}$ from the capital of Lomé (Ineich 2006) although some of the wildlife trade facilities have branches or "depots of animals" in villages elsewhere in the country. This type of "reptile production" was first introduced in West Africa in the 1960s, and became established in Togo in the early 1990s (de Buffrénil 1995). As of 2006, there were seven farms known to be operating in Togo (Ineich 2006; UNEP-WCMC 2014), with an agreed national annual export quota of 62,500 "ranched" specimens and 1,500 "wild" specimens in place since 2007 (UNEP 2019).

The most recent examination of the different python production systems in Togo was carried out by Ineich (2006), following concerns raised by the EU Scientific Review Group in 2005 in relation to an exceeded quota of wild-sourced specimens from Togo, between 1999-2003 (UNEP-WCMC 2005). Ineich (2006) described the UNELAT (Union Nationale des Eleveurs et Exportateurs d'Animaux du Togo - National Union of Animal Breeders and Exporters of Togo) exporting association which was put in place in 2000, in part, to help provide liaison and circulation of local CITES export-authority information. In Togo, all farms, of which four were affiliated with UNELAT, relied on the annual involvement of numerous villagers who hunted snakes and delivered them to these farms prior to export (Ineich 2006).

Ball python "ranching" in Togo (as outlined in UNEP-WCMC 2014) depends on the collection of gravid females and egg clutches, that are found by following tracks in farmland or forest, breaking open hollow palm trunks, and / or digging up abandoned rodent burrows (Harris 2002). According to Ineich (2006), exporters also trained Togolese "producer" villagers and provided them with the necessary equipment for temporarily keeping gravid females and hatching eggs, before selling the resulting juveniles to the farms. A key stage of this ranching system involved releasing the females after they had laid their eggs and also a proportion of the juvenile ball pythons produced annually (stated to be $20 \%$ at that time, Ineich 2006; UNEP-WCMC 2014). However, Ineich (2006) also reported that hunters collected non-gravid and male ball python specimens, together with non-CITES listed reptile species for direct export via the farms (Ineich 2006).

Ineich (2006) concluded that the practice of ball python ranching in Togo was being done in relatively healthy conditions. He suggested that (1) the technical knowledge of the exporters had improved between 2004 and 2006, (2) capabilities of the CITES authorities had likewise improved, and (3) the exporters / authorities exchanges were "excellent" and therefore constituted a solid basis for the future with exporters showing willingness to perfect the management and monitoring of the ball python populations that they exploit (Ineich 2006). However, Ineich's (2006) review, which was broadly supportive of the different python production systems in Togo, was carried out over a decade ago. In the fast-moving arena of wildlife trade, subject to increasing consumer demand and often dependent on wild populations of unknown size and status, we considered it timely to provide an update on this situation in Togo, focusing specifically on the practices, and role of, local hunters. 
With that aim, we present here data on the hunting activities of 58 rural hunters involved in the harvest of ball pythons in southern Togo. The specific objectives of our study were:

(1) To describe how ball pythons are harvested and how this activity relates to trade regulations.

(2) To gain insights into the potential impacts this activity might have on ball python conservation.

(3) To gain insights into the extent to which this activity supports local livelihoods.

\section{Methods}

\section{Study area}

The Togolese Republic is a relatively small West African country located between Burkina Faso (in the North), Ghana (in the West), Benin (in the East) and the Atlantic Ocean (in the South). It covers a total land area of $56,600 \mathrm{~km}^{2}$ (Dansi et al. 2013) with a population estimated at about eight million (World Bank 2019). The country is partitioned from North to South into five administrative regions (Savannah region, Kara region, the Central region, the Hills region and the Maritime region) inhabited by 21 principal ethnic groups (Adja, Akposso, Akébou, Ana, Anii, Atchè, Bassar, Ewé, GamGam, Gourma, Ifè, Kabyè, Konkomba, Kotokoli, Lamba, Moba, Para, Tchokossi, Tém, Temmari and Yaka) (Dansi et al. 2013). However, ethnic groups predominantly in neighbouring countries, such as the Fon from Benin, are also present in adjacent parts of Togo (Heath 2010).

Togo has two climatic regions, the Southern and the Central regions characterised by a subequatorial climate with two rainy seasons and two dry seasons and the Northern region with Sudanian climate type, characterised by only two seasons (that is, a rainy season and a dry season) (Afidegnon 1999). As a consequence of its location, the Togolese landscape consists, from south to north, of a succession of ecosystems ranging from coastal grasslands to equatorial and wet tropical forests and ending in Sudan savannahs in the North (Segniagbeto et al. 2011). These diverse ecosystems harbour a great number of animal species, as indicated by the presence of approximately 178 extant species of mammal (Amori et al. 2016), 43 species of lizard (Segniagbeto et al. 2015) and 91 species of snake (Segniagbeto et al. 2011).

\section{Data collection}

We used semi-structured interviews to gather information focused on ball python capturing and egg collecting practices and included questions related specifically to the numbers captured and released, where they were captured, income generated and 
hunters' perceptions of their status in the wild (Suppl. material 1). We interviewed hunters that self-identified as hunting ball pythons, and that were willing to participate in the study, through a process of chain referral (Newing 2011), whereby participants recommended other potential participants or persuaded others to take part. This snowball sampling approach (Babbie 2004) is useful when researchers are interested in the opinions of a particular sector of the population (Potgieter et al. 2017) and, in this case, ensured that participants who could provide information pertinent to the study were selected as representatives of the ball python hunting community. Our primary goal was not to extrapolate to the wider community but to thoroughly understand the activities of the hunters we interviewed on the basis of a comprehensively built questionnaire (Suppl. material 1).

Interviews were conducted by four local field staff asking a set of predetermined questions that included open-ended, closed and multiple-choice questions (Suppl. material 1). Participants were initially asked some non-ball python related questions (including what domestic animals they kept and what type of meat they preferred to eat) to ensure that they were as comfortable and as relaxed as they could be before being asked more detailed questions about hunting ball pythons (Newing 2011). Between 27.08.18 and 24.08.19 interviews were conducted in 20 villages in Ewe and French and later translated into English (Fig. 1).

In accordance with the British Sociological Association Statement of Ethical Practice (BSA 2017), informed consent was obtained verbally from every survey participant prior to the interview, the objectives of the study were explained to participants and they were made aware of their rights to voluntarily participate or to decline, no identifying participant or household data were collected, and the database collated was entirely anonymous.

\section{Data analysis}

All statistical analyses were carried out in R (version 3.3.3; R Core Team 2017). All interviews were included in the analysis even if they contained missing data. Spearman's rank correlation coefficient was used to test for correlations among variables, and nonparametric tests (Mann-Whitney and Kruskall-Wallis tests) to compare among groups. Monetary values were reported in West African CFA Francs (CFA) and converted to US dollars (USD) using $1 \mathrm{CFA}=0.0017 \mathrm{USD}$ (conversion rate as of 26.04.19, xe.com). We used descriptive statistics, and frequency histograms to describe, and to illustrate, patterns and trends in the data. Estimated income from the ball python trade per hunter (I) was estimated as follows:

$I=[($ number of snakes $*$ price per snake $)+($ number of eggs* $\times$ price per egg $)] /$ size of hunting party

* This is the total number of snakes captured and purchased/total number of eggs collected and laid. 


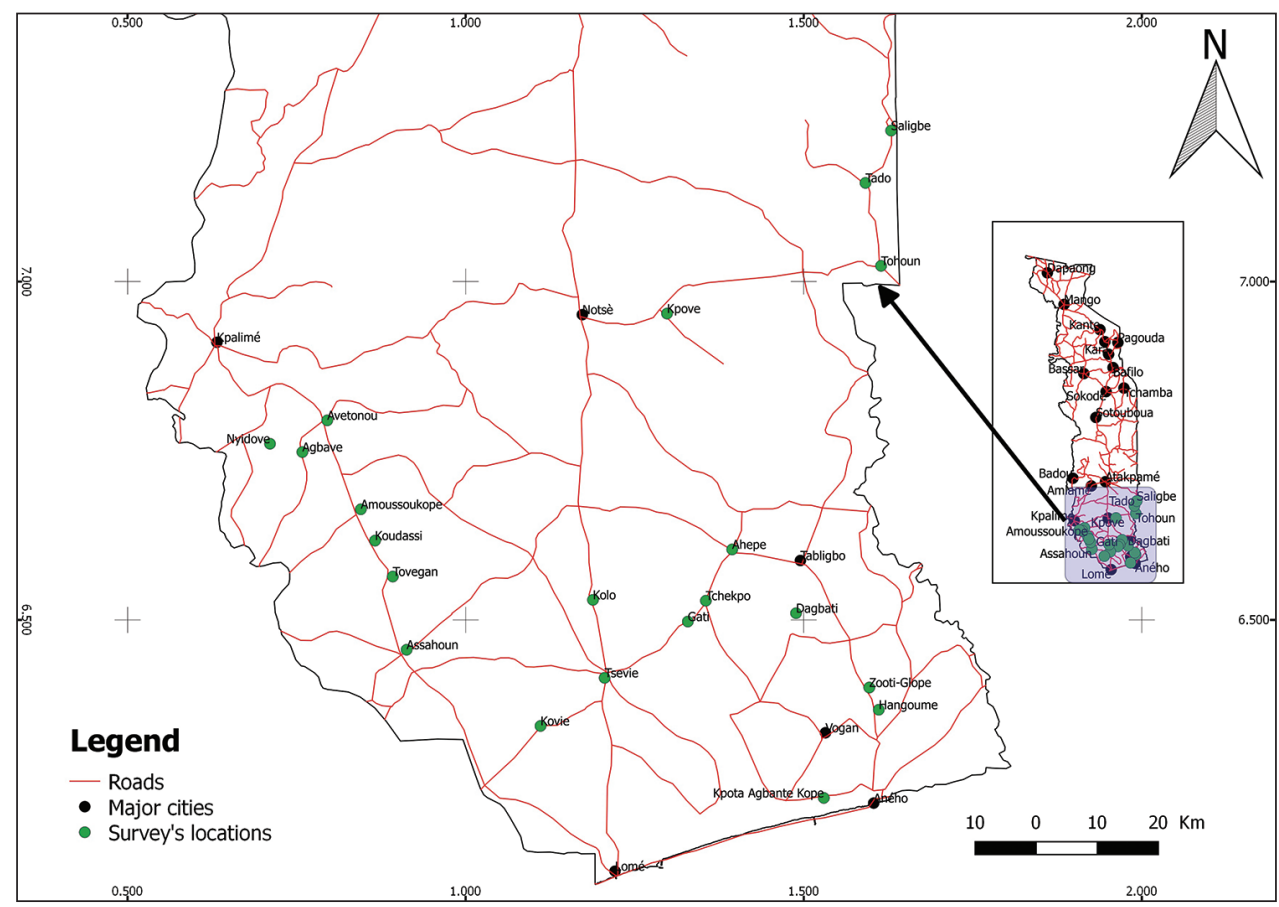

Figure I. Location of the survey site districts in Togo, West Africa.

\section{Results}

Interviews lasted approximately one hour (between 37 minutes and 2 hours 2 minutes). All but three, of a total of 60 interviewees, hunted live ball pythons and collected their eggs (one individual did not hunt them personally but bought live snakes and eggs from other hunters). Hereafter we refer to 60 interviewees as follows; 57 hunters or 58 hunter / traders (noting that some hunters also "trade" by purchasing additional snakes and eggs from other hunters; we discuss this further below).

\section{Hunter demographics}

All but one of the interviewees (a 45-year-old widowed female) were males, 76\% $(n=45)$ of which were in their 30 s or 40 s (age range $=16-61$, mean $=39)$, and $95 \%$ $(n=56)$ of which were married. Most $(77 \% ; n=46)$ owned between one and three houses (maximum = 10; two did not own a house), with between one and eight people in their household (mean $=6.9$, maximum $=25$ ), including between two and six children $($ mean $=4.2$, maximum $=14$; three did not have children).

Most $(73 \% ; n=44)$ interviewees were Watchi / Ewe, $17 \%(n=10)$ were Adja, others included Moba $(n=3)$, Fon, Kabye, and Lamba ( $n=1$ respectively). In terms of their religion, most $(67 \% ; n=40)$ were Christian, although $32 \%(n=19)$ were 
animist, and one was Muslim. Education levels of interviewees were variable; although $38 \%(n=23)$ were educated to secondary level, almost half $(48 \% ; n=29)$ were educated only to primary level, and $13 \%(n=8)$ reported that they had no formal education.

All but one interviewee (a "tailor/python reseller") described themselves as hunters, farmers or both (over half, 62\%; $n=37$, said that they were hunters and farmers). Reported primary source of income was hunting (for $43 \%$ interviewees; $n=26$ ) or farming (for $30 \%$ interviewees; $n=18$ ), other primary sources of income given were "frog hunting" ( $8 \% ; n=5)$, "driving" ( $5 \% ; n=3)$, "retail" $(3 \% ; n=2)$, "breeding" $(3 \% ; n=2)$, "fishing" $(2 \% ; n=1)$ and "ball python reselling" $(2 \% ; n=1)$ (two interviewees stated that they were "studying"). Reported annual wages were variable: 10 interviewees reportedly earned > one million West African Francs (CFA) per year (equivalent to 1,700 USD; maximum 12 million or just over 20,000 USD) but most earned between approximately 100,000 and 600,000 CFA (median $=400,000$ CFA per year or 679 USD; six interviewees earned $<100,000$ CFA per year, minimum 40,000 CFA or 70 USD).

\section{Ball python hunting}

Ball pythons and their eggs were reportedly found by digging abandoned rodent burrows, breaking termite mounds, or by turning over dead oil palm trunks and piles of grass and leaves, and were most likely to be found in forest habitats (reported by $n=$ 49 of 58 hunter/traders, $84.5 \%)$, farmland $(70.1 \% ; n=41)$ or oil palm plantations $(31.0 \% ; n=18)$. Other habitats where pythons could reportedly be found included fallow land $(n=11)$, rice fields owned by the interviewees $(n=5)$, teak plantations ( $n$ $=2$ ), and Casava plantations $(n=1)$; note that hunters gave more than one answer. Pythons were found predominantly between January and March, with eggs collected most commonly in February and March (see Fig. 2). In total, 26\% $(n=15)$ of hunters described locating ball pythons as being dependent on the presence of indirect signs such as tracks (some suggested that tracks could be seen after vegetation fires); similarly, 23\% $(n=13)$ suggested that seeing a basking female ball python near a burrow (or "hole"), or signs that a snake had been basking there previously, indicated the presence of eggs inside the burrow.

Some hunters suggested that they hunted ball pythons as early as November, with peak hunting activity taking place in February and March, up until June (although one hunter said that he hunted ball pythons in August and September) (Fig. 2). Eggs were collected between January and May and as late as June (Fig. 2). All hunters reported hunting live snakes but tended to target either all snakes (male and female, adults and juveniles, $51 \% ; n=29)$ or females and juveniles $(35 \% ; n=20)$; only seven hunters $(12 \%)$ said that they hunted only females; one $(2 \%)$ said that both males and females were hunted [i.e. over half of hunters $(53 \% ; n=30)$ said that they hunted males, as well as females and juveniles]. All hunters also reported that they collected eggs. In addition to describing how they found the eggs, five hunters (9\%) said that to obtain eggs they caught gravid females, and five (9\%) explicitly referred to capturing and keeping 


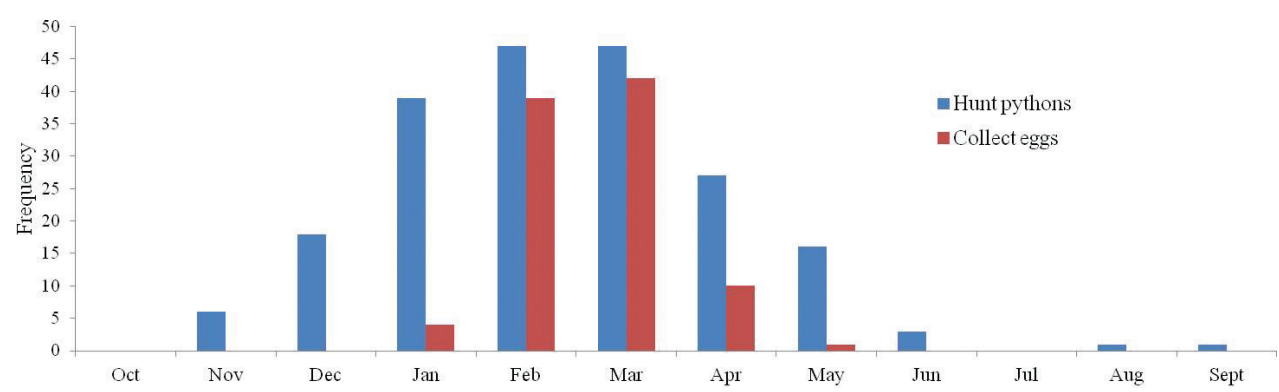

Figure 2. Reported peak months for harvesting ball pythons and their eggs; frequencies are the number of times the month was cited. Note that most hunters gave months as a range rather than a single optimal month so values sum up to more than the number of hunters $(n=57)$.

gravid females until they laid their eggs; two hunters said that they collected the eggs and left the females.

Hunters reported hunting parties averaging 5 hunters (range 1-10), that took part in between two and 150 hunting trips in the last 12 months (excluding one hunter who said he hunted on 300 separate days during this period) (mean $=58$ hunting trips, median $=50$; see Fig. 3a). They also reported capturing between 12 and 3,000 pythons $($ median $=120$; Fig. $3 \mathrm{~b})$ and collecting between 12 and 5,000 eggs $($ median $=150$; Fig. 3c) in total over the 12 months. Five hunters (9\%) (all of whom said they captured female, male and juvenile snakes) reported capturing 1,000 or more pythons in the last year. However, most hunters $(>90 \%[91.2 \%] ; n=52)$ reported capturing a maximum of 500 pythons, and $17(30 \%)$ capturing 50 or less. Similarly, one hunter reported collecting 5,000 eggs, whereas all others $(98 \% ; n=53)$ reported that they did not collect more than 1,000 eggs. In addition, 17 (31\%) individuals reported collecting 100 or less.

Dividing the reported total number of pythons captured in the last 12 months, and the total number of eggs collected, by the reported number of trips undertaken, for each hunter, suggested that hunters were capturing an average of between 0.3 (i.e. one every three or four trips) and 31 ball pythons (median $=2.5$ ), and an average of between 0.3 (one every three or four trips) and 50 ball python eggs (median = 4.3) per trip. Approximately a fifth of hunters were capturing 10 or more ball pythons per trip $(21 \%$; $n=12)$ or collecting 10 or more eggs $(20 \% ; n=11)$; most (ca. $70 \%)$ captured a maximum of five ball pythons per trip $(n=40)$, and fewer than six or seven eggs per trip ( $n=$ 35 and 40, respectively) (most likely a single clutch of eggs). Most ball python clutches comprise five to eight eggs (Aubret et al. 2003), and the eggs are strongly adherent so it is not possible to separate them without damaging the shell (Aubret et al. 2005).

In addition to direct ball python hunting activities, eight interviewees (including those who also captured snakes themselves, and one who only bought snakes and their eggs from hunters) reported purchasing between 2,000 and 3,000 additional ball pythons $($ mean $=1,900$, minimum $=400$, maximum $=2,700$; excluding one interviewee who stated he bought 38,000 ) in the last 12 months. For the seven hunters, this additional purchasing increased their annual "collection" on average five-fold (range one to nine) to an average of 2,500 snakes in total (range $500-3,000$ ). The one interviewee 
$\mathbf{a}$

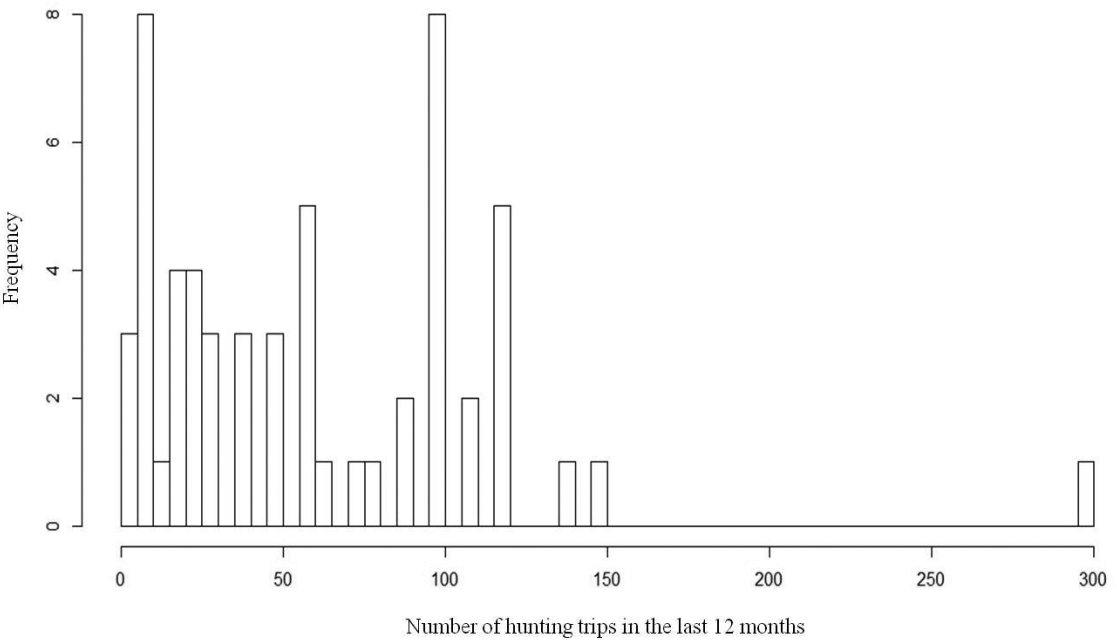

b

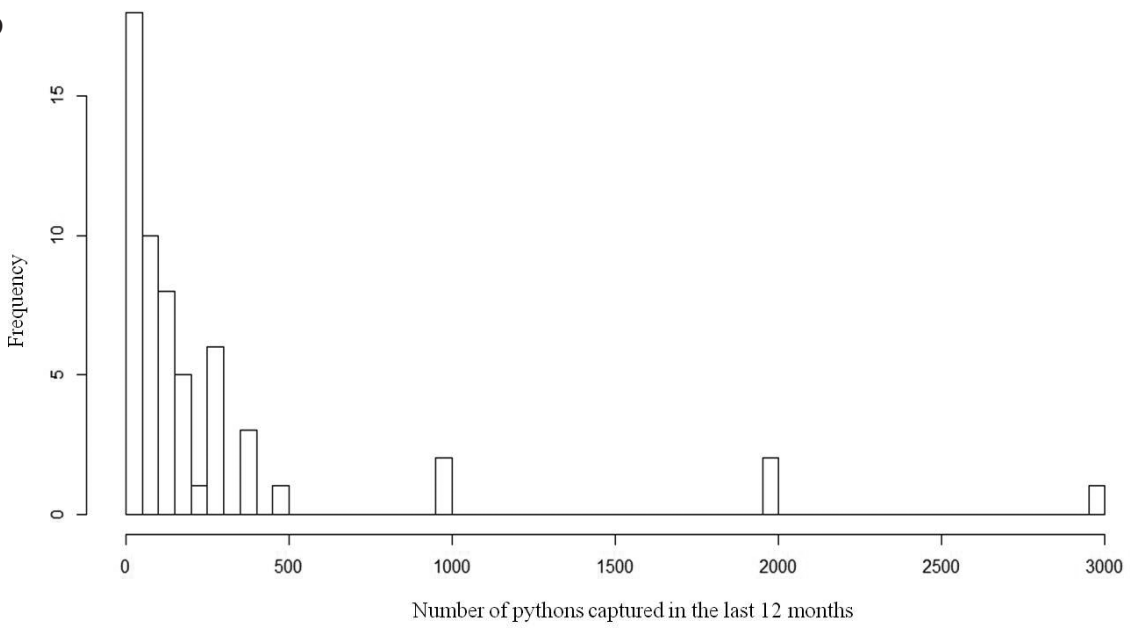

c

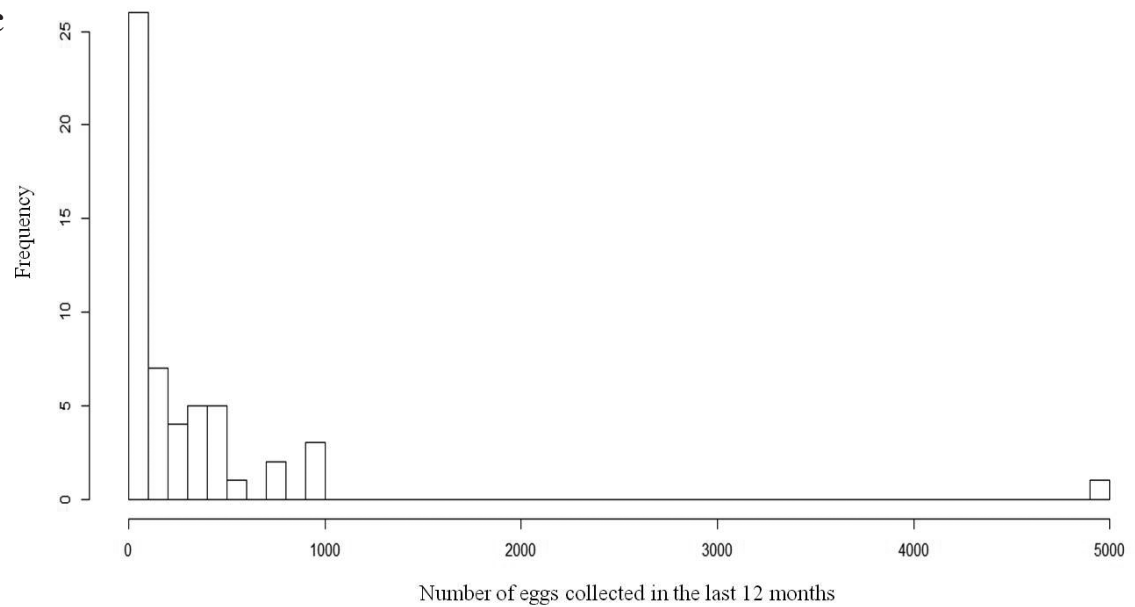

Figure 3. Frequency distribution of number of $\mathbf{a}$ ball python hunting trips $\mathbf{b}$ ball pythons captured and c ball python eggs collected, in the last 12 months as reported by 57 interviewed ball python hunters. 
that only purchased ball pythons reported buying 1,500 individuals. Ten interviewees also reported that between 300 and 2,000 (mean = 1,320) eggs were laid by female ball pythons in captivity during one season prior to onward sale.

All hunters said that they sourced ball pythons in Togo, 60\% $(n=35)$ stated that they sourced ball pythons only in Togo. However, almost a quarter $(23 \% ; n=13)$ stated that they also hunted ball pythons in Ghana, $10 \%(n=6)$ stated that they also hunted in Benin, and 7\% $(n=4)$ stated that they hunted ball pythons in both neighbouring range states. All of the 58 hunter / traders that said they hunted ball pythons, collected their eggs, or bought ball pythons, reported that there were no quotas for either ball pythons or their eggs.

Most hunters / traders $(86 \% ; n=50)$ stated that they released some ball pythons (range 5-1,000; median = 100, in the last 12 months; Fig. 4a) back into the wild. The numbers released were positively and significantly correlated with the numbers captured $(\mathrm{r}=0.54 ; \mathrm{p}<0.001)$ but, on average, were fewer than the numbers captured (slope of regression $\left.=0.68, \mathrm{~F}_{1,49}=24.91, \mathrm{p}<0.001\right)$ and there was considerable variation $\left(\mathrm{R}^{2}\right.$ adjusted $=0.32$ ) such that, at an extreme the numbers released, per hunter, ranged between approximately one tenth and eight times their reported capture (median proportion released $=0.8$; Fig. $4 \mathrm{~b})$. Over half of hunters that released pythons $(58 \% ; n=$ 29) released fewer snakes than they reported collecting. Nine (18\%) hunters obtained ball pythons for release from the snake farms, 14 (28\%) from the "middlemen", and 27 (54\%) did not say.

Most $(64 \% ; n=32)$ of the 50 hunter / traders that released ball pythons back into the wild stated that they released ball pythons to allow them to reproduce again; others said, so that they could be captured again next year $(12 \% ; n=6)$, or to avoid impact on population size or make the hunting sustainable $(6 \% ; n=3)$. One hunter said explicitly that he released snakes in [his] hunting area in order to come back to capture them the following season. Most hunter / traders $(66 \% ; n=33$ of 50$)$ stated that they released females, some also stated that they released females and juveniles $(16 \% ; n=8)$, females and males $(8 \% ; n=4)$, all sexes and age classes [males, females and juveniles, $(6 \%$; $n=3)$ ], or just males $(4 \% ; n=2)$.

With regards to release habitat, $18 \%(n=9)$ stated that they released snakes into the forest. Others stated that they released snakes into farmland $(6 \% ; n=3)$, fallow land $(2 \% ; n=1)$, or, in most cases $(68 \% ; n=34)$, a combination of forest, farmland, and / or fallow land; $6 \%(n=3)$ said that they released ball pythons into either farmland or oil palm plantations.

\section{Drivers of ball python harvest}

Only two of the 60 interviewees (3\%) said that they had collected ball pythons for personal consumption (both said that they liked to consume python meat occasionally and that they had slaughtered one and seven ball pythons in the last 12 months, respectively). The vast majority of interviewees $(93 \% ; n=56)$, however, said that they did not eat either ball pythons specifically $(65 \% ; n=39)$, or snakes more generally 


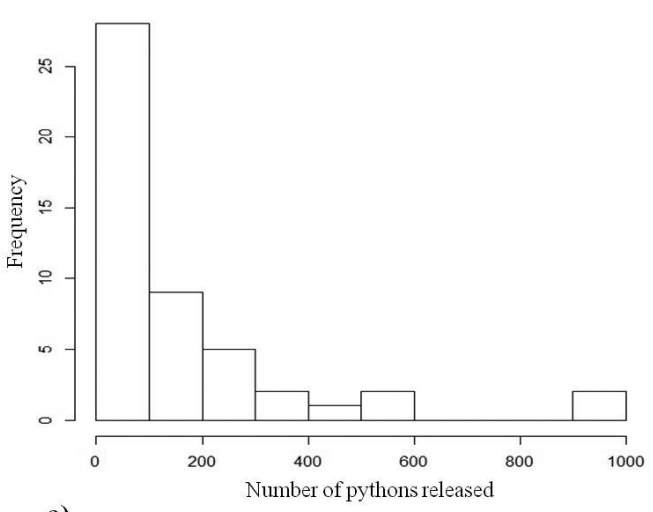

a)

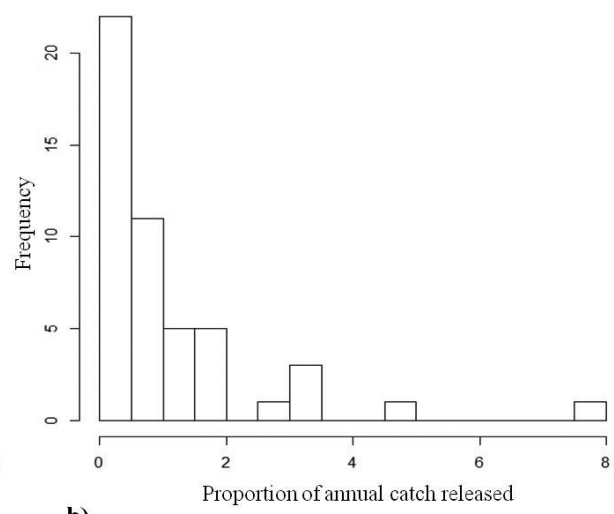

b)

Figure 4. Numbers of ball pythons released back into the wild, shown as the frequency distribution of $\mathbf{a}$ reported numbers released, and $\mathbf{b}$ reported numbers released as a proportion of the reported numbers captured, in the last 12 months, based on answers given by 50 python hunters that released pythons at the end of the hunting season.

$(28 \% ; n=17)$, primarily because ball pythons are considered as sacred $(27 \% ; n=15$ of 56 that stated that they did not eat ball pythons / snakes) and / or because it is not allowed in their society and culture $(45 \% ; n=25)$.

None of the 58 hunter / traders said that they kept ball pythons as pets themselves, and none reported either using or selling ball python body parts (skins, bones or blood). Instead, all 58 hunters / traders said that they sold ball pythons and their eggs, either via "middlemen" outside $(43 \% ; n=25)$ or inside $(19 \% ; n=11)$ their village, or directly to snake farms $(38 \% ; n=22)$ or both $(2 \% ; n=1)$. Four hunter / traders $(7 \%)$ sold ball pythons to snake farms in Benin $(n=3)$ or Ghana $(n=1)$. None sold ball python meat but five (9\%) sold pythons and / or their eggs to Chinese restaurants in Lomé, the capital city of Togo.

Reported prices obtained for live ball pythons and their eggs varied greatly, for ball pythons between 1,200 and 10,000 CFA (median =3,000, or between 2 and 17 USD, median $=5$ USD), and for their eggs between 200 and 2,500 CFA (median $=500$, $<0.5$ to 4 USD, median $=0.9$ USD). However, almost half of hunter / traders ( $44 \%$; $n=26)$ reportedly sold snakes for 2,000 CFA (3.4 USD) or less $(<10 \%, n=5$, sold snakes for 10,000 CFA, or as much as 17 USD), and, the majority $(93 \% ; n=52)$ sold eggs for 1,000 CFA (1.7 USD), or less (see Fig. 5).

Per hunting party, estimated annual income from ball python hunting (based on the reported number of snakes captured and the prices they were sold for, see Eqn. 1, Methods) ranged between 24,000 and 24 million CFA (median = 300,000 CFA; or between 41 and 41,000 USD, median $=510$ USD), whilst that from egg collection (based on the reported number of eggs collected and the prices they were sold for) ranged between 6,000 and 7.5 million CFA (median = 90,000 CFA; between 10 and 12,750 USD; median $=153$ USD), giving a total ball python harvest income of between 46,000 and 31.5 million CFA (median = 540,000 CFA; between 78 and 53,550 USD, median $=918$ USD). The average estimated income of one hunter, ranged be- 




Figure 5. Sale price for ball pythons (green) ( $n=58$ hunter / traders), and ball python eggs (red) ( $n=$ 56 hunter / traders that gave prices for eggs), in West African CFA Francs (CFA) (1 CFA $=0.0017$ USD, conversion rate as of 26.04 .19 , xe.com).

tween 12,250 and 5.25 million CFA (median =102,250 CFA; between 20.8 and 8,925 USD, median $=173.8$ USD), amounted to between 3 and $169 \%$ of a hunter's reported annual wages $($ median $=40 \%)$.

The highest reported prices (10,000 CFA for snakes and 2,500 CFA for eggs; 17 and 4.3 USD, respectively) were for sales to Chinese restaurants. Prices also tended to be higher when sold direct to farms or to middlemen outside the village than to middlemen inside the village (for ball pythons: median price obtained from sales to farms and middlemen outside the village $=3,000$ CFA or $5.1 \mathrm{USD}$, middlemen inside the village $=2,000$ CFA or 3.4 USD, Kruskal-Wallis $\chi^{2}=9.72, \mathrm{df}=2, \mathrm{p}=0.008$; for their eggs: median price obtained from sales to farms $=1,000$ CFA or 1.7 USD, middlemen outside the village $=500 \mathrm{CFA}$ or $0.9 \mathrm{USD}$, middlemen inside the village $=300 \mathrm{CFA}$ or 0.5 USD, Kruskal-Wallis $\chi^{2}=19.03, \mathrm{df}=2, \mathrm{p}<0.001$ ).

Hunter / traders $(45 \% ; n=26)$ further reported that the price of live snakes depended on the stage of the hunting season and the age class of the snake $(57 \% ; n=33$, with one hunter / trader reporting higher prices for gravid females), as well as "trends in the market" $(14 \% ; n=8)$ and the effects of supply and demand $(16 \% ; n=9)$. One hunter remarked, if we have a lot of specimens and orders are scarce, the price per unit drops. But on the contrary, if we don't have python and the order is high (in terms of number), the price increases.

\section{Attitudes towards ball pythons and perceived population trends}

When asked how they felt about ball pythons (on a scale of 1 to 5 , with 1 being strongly dislike and 5 strongly like), there was a strong bias towards liking ball pythons, with 
$97 \%(n=58)$ of all 60 interviewees stating that they either quite liked $(42 \% ; n=25)$ or strongly liked $(55 \% ; n=33)$ ball pythons (two interviewees stated that they disliked them). All 58 interviewees that said that they liked ball pythons suggested that the benefits provided by ball pythons were related to money or income; nine (16\%) of these 58 specifically referred to money to take care of their children, and four (7\%) referred to it as an important source of income (i.e. that without [it], things would be very hard or difficult). When asked why they felt this way (i.e. why they liked ball pythons), 45 $(78 \%)$ of the 58 interviewees referred to ball pythons as not being dangerous or venomous, and three (5\%) said they could have fun with it. The two interviewees who did not hunt or trade ball pythons said that they had no benefit. One hunter also said that ball pythons regulate the population size of rodents that destroy our crops.

Overall, most interviewees $(75 \% ; n=45)$ stated that there were fewer ball pythons than there were five years ago: $67 \%(n=40)$ stated that there were quite a few less, $8 \%$ $(n=5)$ stated that there were a lot less, while $7 \%(n=4)$ that there were more, and $17 \%(n=10)$ that there were the same number; one did not answer the question. Of the 45 interviewees that referred to an apparent decline in ball pythons in the last five years, 17 further commented on the possible cause of a decline (note that they were not asked this question directly). Eleven of 17 interviewees that commented on the cause of a decline referred directly to hunting, or to increasing numbers of hunters and farms (one stated that As we are capturing them with their eggs, they don't have time to reproduce anymore), four referred to tractors and cows (trampling), two to forest destruction, two to uncontrolled vegetation fires $(n=2)$, and one to climate change (prolonged dry seasons).

\section{Discussion}

This study represents the first review of ball python hunters and their experiences being carried out by local groups in Togo, West Africa for nearly 15 years (see Ineich 2006), and provides an assessment of a large-scale contemporary production system to supply live reptiles (exported as "ranched" using CITES source code "R") to the international pet trade. Our approach, focused at the bottom of the trade chain, permitted extensive detailed data to be collected from hunters, and provides a unique insight into the practices, drivers and impacts associated with this type of large-scale commercial wildlife trade (Fig. 6). We found that the practice of ball python hunting is an important source of income for those hunters involved. However, whilst our data do not include precise numbers of gravid females and adult males collected, or of juvenile production, there was little evidence of regulatory oversight at the hunter level with regard to (1) the release of females after they have laid their eggs, (2) release of $20 \%$ of the juveniles produced, or (3) collection of adult males within quotas for wild-caught specimens, as required under national management plans and CITES. Further, widespread suggestion among hunters that wild ball python populations have declined raises concern regarding the sustainability of this practice. Overall, we found little evidence of effective management, as outlined by Ineich (2006). 




Figure 6. A hunter digging for a ball python (Python regius) B ball python uncovered from a rodent burrow $\mathbf{C}$ ball python eggs intended for commercial sale $\mathbf{D}$ Hunter with his catch of live ball pythons intended for commercial sale in Togo, West Africa. Images A-C Mark Auliya / World Animal Protection; image D, Delphine Ronfot / World Animal Protection.

On average, ball python hunting parties are typically composed of around five individuals that take part in around 50 hunts each year collecting 120 ball pythons and 150 eggs each. However, the roles of these individuals can extend beyond hunting (Fig. 7). We found that a proportion of hunters also act as middlemen $[(14 \% ; n=8)$ buying between 2,000 and 3,000 ball pythons from other hunters over the last year] and $(17 \% ; n=10)$ are also involved in the "ranching" of ball pythons (keeping gravid females at home until they have laid their eggs which are then sold to farms, as suggested by [Ineich 2006]). 


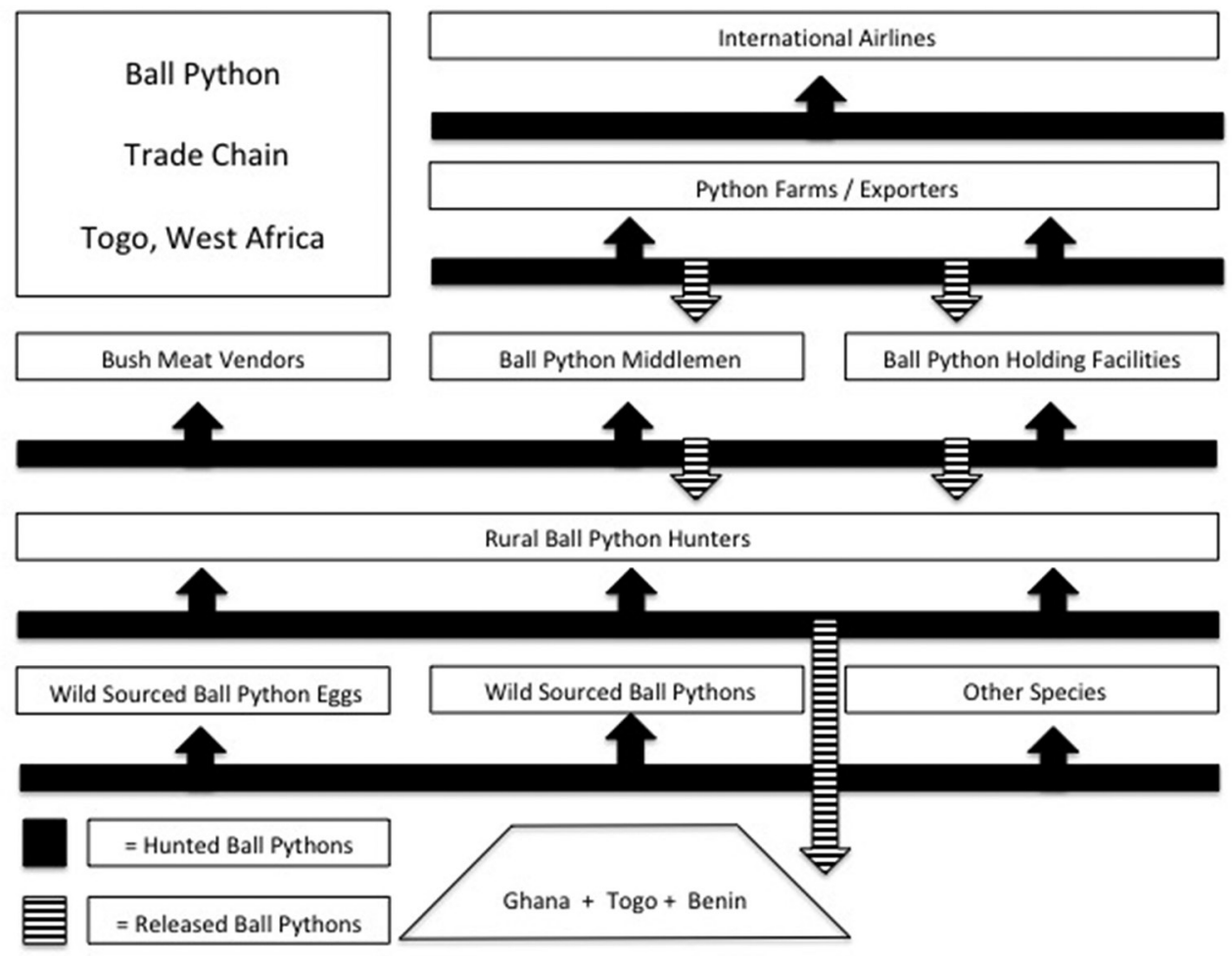

Figure 7. Ball python "chain of custody" demonstrating the various trade actors involved in commercial trade activity in Togo, West Africa. Ghana and Benin are included as source countries for wild caught ball pythons as per described by 23 hunters during interviews.

\section{Why are hunters targeting ball pythons in Togo?}

Our study demonstrates that ball python hunting remains an economically valuable endeavour for rural hunters in Togo, West Africa. Although ball python and egg hunting appear to be seasonal, taking place predominantly between the months of January and April, we estimate that, on average, a hunter receives 102,000 CFA (174 USD) from python and egg sales combined, representing approximately $40 \%$ of their annual income. Despite a degree of variability, collection rates reported by some hunters suggests that they can earn up to 5.3 million CFA (approximately 9,000 USD) from python and egg sales combined representing approximately 169\% (almost double) their average annual income.

Overall, hunters described the sale of live ball pythons (maximum estimated annual income per hunting party of 24 million CFA) as a more financially lucrative endeavour than the sale of python eggs (maximum estimated annual income per hunting party of 7.5 million CFA). Although, on average, hunters collected approximately the same number of eggs as they captured snakes, the latter were reportedly worth approxi- 
mately five times as much as a single egg. The lower value of eggs is presumably due to factors such as higher mortality rates in eggs and neonates, while gravid females are of presumably particularly high value because they will produce several offspring.

\section{Is ball python hunting being conducted legally?}

Our study reveals that some key aspects of python hunting taking place in Togo may run afoul of domestic and international legal requirements. For example, Article 78 of Law No. 2008-09 of the Carrying Forest Code strictly prohibits the hunting of gravid females, newborns, juveniles, eggs and the associated destruction of ball python burrows. Furthermore, Articles 79 and 80 of the Carrying Forest Code allow certain hunting activities, but the number of hunters that possess the required hunting permits is currently unknown. Another unknown is whether hunters possess the professional licence required under Article 81 of the Carrying Forest Code. In addition, Article 61 of the 005 Framework Law on the Environment participative manner to ensure its sustainability, which for ball pythons is questionable (also see below).

With regards to international regulations, our findings suggest that both exporter country and CITES source codes are in fact misrepresentative. Forty percent $(n=23)$ of the 58 hunter / traders interviewed during our study stated that they source ball pythons outside of Togo and 7\% stated they sold them back to snake farms in Benin and Ghana meaning that reported exports from Togo, Benin and Ghana by CITES are in reality composed to at least some degree of snakes also sourced from neighbouring countries. In addition, $85 \%$ of the 58 hunters / traders stated that they hunt not only female ball pythons but also males and juveniles, which were then also sold to farms for export. This suggests that ball pythons exported from Togo are composed to at least some degree of snakes also sourced from the wild rather than "ranched" - although export of some wild-sourced specimens is permitted under CITES permit; the agreed quota is currently 1,500 (UNEP 2019). The number of adult snakes collected by hunters for direct export via farms is not known, but this "mixed" system creates considerable opportunity for mis-reporting (cf. Toudonou 2015), and once the snakes are in the farms it is difficult, if not impossible, to distinguish between wild-sourced and "ranched" specimens - a system that lacks transparency. At a regional level, this cross-border hunting activity, together with the misreporting of source codes, undermines domestic legal measures taken by neighbouring source countries: for example, Benin reduced their own quota for wild-sourced specimens in 2019 to 200 individuals (UNEP 2019) to regulate harvest in their country.

\section{What are the impacts of hunting on ball pythons?}

Although the global conservation status of the ball python has been assessed Least Concern according to the IUCN Red List of Threatened Species, population esti- 
mates for ball pythons in West African ecosystems remain lacking (Auliya and Schmitz 2010). Despite their relatively wide distribution and adaptability to anthropogenicallyaltered habitat, regional concerns have already been raised about the impact of live python trade on the conservation of this species (e.g., Harris 2002; Toudonou 2015). Currently, there is no formal population monitoring initiative in place and as such it is not possible to assess whether or not this level of exploitation is sustainable. However, additional large-scale domestic use as bush meat and traditional medicine throughout its range (Harris 2002; Auliya and Schmitz 2010; Segniagbeto et al. 2013; D'Cruze et al., in prep.) and hunter perceptions of ball python population declines raise questions in this regard. We did not attempt to infer the cause of the perceived decline in ball python numbers and there are a number of additional factors that could cause such a decline, including habitat loss (i.e. expansion of agricultural areas into protected areas; see e.g., Harris 2002) and climate change (i.e. increasing frequency and duration of droughts; see e.g., Reading et al. 2010). However, these effects are not isolated, and habitat loss, for example, can increase a populations' vulnerability to overutilization if the population becomes smaller or less resilient as a result and harvest levels remain the same (Regehr et al. 2017; see also Schai-Braun et al. 2019 for discussion of necessary adjustments to harvest quotas in response to population fluctuations caused by climatic events).

A key assumption of the current management process that underpins the export of ball pythons reported as "ranched" from Togo is that wild release is carried out to balance this off take. However, our study highlights that in Togo this may not be carried out effectively. Although $86 \%$ of hunters stated that they released ball pythons back into the wild, the fact that more snakes were captured than were released suggests that the release of all females, in addition to the release of a proportion of offspring produced on the farms, is not being carried out as agreed national management regulations require. Furthermore, there are also questions regarding whether the re-release of ball pythons is being managed to avoid the introduction of disease (Auliya et al., in prep.).

In addition to questions regarding sustainability, there are a number of animal welfare issues associated with hunting practices currently being applied in Togo. Reptiles are recognised in the limited relevant research as being capable of a range of intellectual abilities and states including anxiety, distress, excitement, fear, frustration and pain (Lambert et al. 2019) suggesting that ball pythons, like other reptiles, have the capacity to experience suffering during capture, restraint, transport and subsequent captivity (Baker et al. 2013). We were not able to collect data on ball python morbidity and mortality rates during hunting and holding at farms. However, according to Harris (2002), the directors of two farms reported an estimated mortality rate between 1-2\% at their facilities, and 1-5\% during international transport; the latter information as the author notes, needs to be interpreted with caution as "importers ... often falsify this data to increase profit". Further information on this matter would, in addition to quantifying efficiency of the system, provide insight into the extent and severity of animal welfare issues, but it is likely that snakes suffered stress during capture (in most cases physical removal from rodent burrows) and transport (live, in sacks filled with other 
snakes) and possible that they sustained physical injuries - either or both may result in death or increased susceptibility to disease and / or infection (Baker et al. 2013). A proportion (17\%) of hunters stated that they also kept gravid females themselves at home until their eggs were laid (which were then sold directly to farms). Whilst also not formally part of the study, post hoc visits to a number of hunters' "holding facilities" revealed sub-optimal captive conditions, and morbid animals with little to no veterinary, hygiene or disease transmission protocols in place.

\section{What are the limitations of our study?}

Caution is required in interpreting data derived from hunter interviews (e.g., Newton et al. 2008). For example, interviewees might have been reluctant to be honest about the magnitude of ball python hunting activities and there is a risk that the data underestimate overall hunting levels. Conversely, there is also a chance that some of the hunters may have overestimated their hunting success, or the value of their catch. In this study, it was puzzling that for some hunters the calculated proportion of their income provided by ball python hunting was greater than their reported annual income - this may in part be due to such overestimates (whether intentional or not) and / or to the cumulative effect of potential minor over-estimates for all variables included in the calculation. It is also possible that profits were not divided equally amongst all members of the hunting party, thus overestimating the total income generated for those receiving a smaller share. There are also further complicating factors such as the costs involved in purchasing additional snakes and eggs, and for this reason we did not include those hunters involved in further trading in our estimates of total income generated, but it is likely that this additional trading is potentially lucrative. Nevertheless, regardless of the precise proportion of total income provided by python hunting, our calculations suggest that it is currently substantial.

In addition, it was not possible to learn whether hunters only collected females with clear evidence of them being gravid, and / or whether they collected all females after the mating period, i.e. only assuming that they were gravid? Similarly, we do not know how many adult males were collected, how many adult females were released (post egg laying), or what proportion of juveniles produced in farms were in fact rereleased. Also, we do not know whether wild captured specimens are intended for the purpose of consuming or supplying bush meat (markets) to other parts of the country or even across the country's border to Benin (Toudonou 2015), or even Nigeria (Eniang et al. 2006).

Our aim was not to assess the extent of impact or the total number of people involved, rather we sought to understand the practices undertaken by those who were willing to discuss that they hunted pythons and their reasons for doing so, and to assess whether there was cause for potential concern that might warrant further study. That 58 hunter / traders were willing to talk to us and that $40 \%(n=23)$ openly admitted to an irregular if not illegal sourcing of ball pythons from neighbouring countries without 
required CITES permissions suggests that they were being truthful. That 45 hunter / traders believed that ball python numbers were declining suggests further monitoring is required. According to Gorzula et al. (1997), there was "sufficient hearsay evidence to suggest strongly that ball pythons are being smuggled from Ghana to Togo and Benin". Furthermore, Ineich (2006) stated that juvenile ball pythons originating from Benin are legally and illegally brought to Ghana. The overall similarity in the answers from hunters across 20 different villages from eight different districts, that might be located up to $100 \mathrm{~km}$ from each other, further suggests the validity of the data and the seriousness of our findings.

\section{How can we protect ball pythons and people?}

It is clear that hunting ball pythons to supplement the international exotic pet trade is a valuable source of income for the hunters currently engaged in this commercial trade. However, the long-term viability of this activity as a source of financial income is jeopardised by an apparent increase in the number of captive-bred ball pythons in key importing countries such as the USA (Barker and Barker 2006), and the increasing role of the USA (and some European countries) as a global exporter of captive-bred ball pythons (CITES Trade Database, https://trade.cites.org). A detailed analysis of international market forces is beyond the scope of our study. However, it appears that even if both demand for, and quotas for, ball pythons remained stable, the number of hunters required to meet current demand remains relatively small.

Currently, the ball python quota from Togo is set at 62,500 ranched individuals and 1,500 wild caught individuals (UNEP 2019). On average, the hunters interviewed during our study indicated that they harvested 120 live ball pythons to supplement the ranching process during a 12-month period. Assuming that each snake survived to produce one clutch of eight eggs (Aubret et al. 2003), all of which provided viable hatchlings, only approximately 61 hunters would be required to meet the 62,500 ranched individual quota currently put in place by Togo. Should consumer demand for ball pythons in key foreign markets shift away from ranched and / or wild captured ball pythons from West Africa, sustainable alternative livelihood initiatives (D'Cruze et al. 2010) may be useful in helping hunters to find new viable forms of income.

From a legal perspective, it is apparent that there are a number of complex and potentially conflicting pieces of legislation that relate to ball python hunting and subsequent commercial trade. As such, a streamlining exercise for the various existing pieces of domestic legislation would greatly benefit efforts to protect remaining wild ball python populations in Togo. The apparent intention of the Togolese authorities to update its capacity relating to the implementation of CITES would present an excellent opportunity to provide clarity and improved enforcement in this regard. Indeed, it is not clear that the source code R is appropriate for the "ranching" system described here, given the inclusion of the collection of gravid females, and other uncertainties such as how long offspring are held at farms for "rearing" prior to export. 
In addition, clarification on the circumstantial requirements of ball python hunting licences and the penalties associated with violating relevant legislation is urgently required. Furthermore, the cross-border hunting activity reported during our study supports previous recommendations for increased control in the harvest and release of ball pythons (e.g., de Buffrénil 1995) and highlights the current need to define common legal tools in a tripartite agreement between the three main ball python range states in West Africa that are predominantly involved in their commercial export (Benin, Ghana and Togo).

Ultimately, confidence in the long-term sustainability of current ball python hunting practices, in terms of a source of financial income and wild population survival, is currently undermined by a lack of data on the status of wild ball python populations. Such data are essential to assign appropriate quotas (cf. Schai-Braun et al. 2019) that protect both people and ball pythons and are an urgent priority in this regard. However, such initiatives can be difficult to implement, time consuming and costly to fund (D'Cruze et al. 2009). In the interim, in light of the unregulated and potentially unsustainable nature of ball python hunting in Togo highlighted by this study, a revision of the Togo export quota should be considered as part of a more precautionary approach. Benin appears to have already taken such preventative action, recently reducing its export quota from 45,000 specimens that were exported as ranched in 2017 to 22,000 in 2018 and 2019 (UNEP 2019). Given the recognised current financial value of the international trade in Ball pythons to hunters in Togo, direct monetary compensation [e.g., payments for ecosystem services (Clements et al. 2010)] may prove useful to help minimize any unintended negative economic impacts on local communities.

\section{Conclusion}

Our study suggests that the ball python production methods applied on the ground in Togo do not accurately reflect (1) offtake levels reported in CITES trade data, (2) the methods being reported to national authorities or international regulatory mechanisms such as CITES, in terms of source country, (3) the extent to which current production methods are dependent on wild-sourced ball pythons, and (4) aspects of management practice (such as re-release of females and a proportion of juveniles). This irregular, if not illegal trade may also be unsustainable, for example as implied by hunters reporting that there are fewer ball pythons in the wild than there were five years ago. Although our study was focused only on Togolese hunters, it is clear that cross-border harvesting is taking place in Benin and Ghana. As such it is likely that these issues are not only restricted to Togo. In short, we highlight a number of uncertainties in the "ranching" process of ball pythons in Togo, and neighbouring countries, upon which legal, sustainable and humane trade depends, and that warrant further study. To create a trade that is transparent in all respects, we support previous conclusions that a solution cannot be sought at the national level but must also involve the neighbouring states Ghana and Benin (e.g., Jenkins 1998; Gorzula et al. 1997). A tri-state common strategy would need to be developed to reorder the trade with ball pythons for all stakeholders in terms of sustainability and traceability of animals (origin, source). 


\section{Acknowledgements}

We wish to thank all of the hunters for their participation and patience during our study and all of the Masters students from the Ecology and Wildlife Management programme, from the Laboratory of Ecology and Ecotoxiology, Faculty of Sciences, University of Lomé (Kossivi Inès Akagankou, Afi Florence Konko, and Kafui Jeanne Dekawole) who helped us to conduct the survey. We also thank Komina Amevoin and Guillaume Koffivi K. Ketoh for their on-going support and collaboration. Mark Auliya and Lauren Harrington received a grant from World Animal Protection to carry out this research. Finally, we sincerely thank Agbo-Zegue NGO for providing necessary logistics for the study.

\section{References}

Afidegnon D (1999) Les mangroves et les formations associées du Sud-Est du Togo: Analyse écofloristique et cartographie par télédétection spatiale. PhD Thesis, Université Benin, Togo.

Amori G, Segniagbeto GH, Decher J, Assou D, Gippoliti S, Luiselli L (2016) Non-marine mammals of Togo (West Africa): An annotated checklist. Zoosystema 38(2): 201-244. https://doi.org/10.5252/z2016n2a3

Aubret F, Bonnet X, Shine R, Maumelat S (2003) Clutch Size manipulation, hatching success and offspring phenotype in the ball python (Python regius). Biological Journal of the Linnean Society. Linnean Society of London 78(2): 263-272. https://doi.org/10.1046/j.10958312.2003.00169.x

Aubret F, Bonnet X, Shine R, Maumelat S (2005) Why do female ball pythons (Python regius) coil so tightly around their eggs? Evolutionary Ecology Research 7: 743-758.

Auliya M (2003) Hot Trade in Cool Creatures: A Review of the Live Reptile Trade in the European Union in the 1990s with a Focus on Germany. TRAFFIC Europe, Brussels.

Auliya M, Schmitz A (2010) Python regius. The IUCN Red List of Threatened Species 2010: e.T177562A7457411. https://doi.org/10.2305/IUCN.UK.2010-4.RLTS. T177562A7457411.en

Babbie ER (2004) The Practice of Social Research (10 ${ }^{\text {th }}$ ed). Thomson/Wadsworth, Belmont, $493 \mathrm{pp}$.

Baker SE, Cain R, van Kesteren F, Zommers ZA, D'Cruze N, Macdonald DW (2013) Rough Trade: Animal Welfare in the Global Wildlife Trade. Bioscience 63(12): 928-938. https:// doi.org/10.1525/bio.2013.63.12.6

Barker DG, Barker TM (2006) Pythons of the World Volume II: Ball pythons. VPI Library, Boerne, Texas.

Brant WE (2001) Commercial production of reptiles for the US pet trade. IUCN SSC - Commercial captive propagation and wild species conservation. Selected background papers. White Oak Foundation, Jacksonville.

BSA [British Sociological Association] (2017) Statement of Ethical Practice. BSA Publications. www.britsoc.co.uk/media/24310/bsa_statement_of_ethical_practice.pdf

Bush ER, Baker SE, Macdonald DW (2014) Global Trade in Exotic Pets 2006-2012. Conservation Biology 28(3): 663-676. https://doi.org/10.1111/cobi.12240 
Clements T, John A, Nielsen K, An D, Tan S, Milner-Gulland EJ (2010) Payments for biodiversity conservation in the context of weak institutions: Comparison of three programs from Cambodia. Ecological Economics 69(6): 1283-1291. https://doi.org/10.1016/j. ecolecon.2009.11.010

D'Cruze N, Henson D, Olsson A, Emmett D (2009) The Importance of herpetological survey work in conserving Malagasy biodiversity: Are we doing enough? Herpetological Review 40: $19-25$.

D’Cruze N, Kumar Sarma U, Mookerjee A, Singh B, Louis J, Prasanna Mahapatra R, Prasad Jaiswal V, Kumar Roy T, Kumari I, Menon V (2010) Dancing bears in India: A sloth bear status report. Ursus 22(2): 99-105. https://doi.org/10.2192/URSUS-D-10-00033.1

D'Cruze N, Paterson S, Megson D, Warwick C, Coulthard E, Norrey J, Auliya M, Carder G (2020) Dropping the Ball? The welfare of Ball Pythons traded in the EU and North America. Animals (Basel) 10(3): 1-413. https://doi.org/10.3390/ani10030413

Dansi A, Dantsey-Barry H, Dossou-Aminon I, N’Kpenu EK, Agré AP, Sunu YD, Kombaté K, Loko YL, Dansi M, Assogba P, Vodouhè R (2013) Varietal diversity and genetic erosion of cultivated yams (Dioscorea cayenensis Poir - D. rotundata Lam complex and D. alata L.) in Togo. International Journal of Biodeversity and Conservation 5: 223-239.

de Buffrénil V (1995) Les élevages de Reptiles du Bénin, du Togo et du Ghana. Rapport d'étude réalisée pour le Secrétariat de la CITES, Juin 1995: 1-23.

Eniang EA, Egwali E, Luiselli L, Ayodele I, Akani GC, Pacini N (2006) Snake bushmeat from the forest markets of south- eastern Nigeria. Natura (Milan) 95: 33-46.

Gorzula S, Nsiah WO, Oduro W (1997) Survey of the Status and Management of the Royal Python (Python regius) in Ghana. Part 1. Report to the Secretariat of the Convention on International Trade in Endangered Species of Wild Fauna and Flora (CITES). Geneva, 38 pp. http://ec.europa.eu/environment/cites/pdf/studies/royal_python_ghana.pdf

Harris M (2002) Assessment of the status of seven Reptile species in Togo. Report to the Commission of the European Union, ref. EC 9810072: 1-58. http://jncc.defra.gov.uk/pdf/ togo_sevenreptilespeciesvpt1.pdf

Heath E (2010) Fon - Ethic group of the Republic of Benin whose ancestors built the powerful precolonial Kingdom of Dahomey; also called Agadja. In: Appiah KA, Gates HL (Eds) Encyclopedia of Africa. Oxford University Press, Oxford/New York, 1392 pp. 10.1093/ acref/9780195337709.001.0001

Herrel A, Meijden A (2014) An analysis of the live reptile and amphibian trade in the USA compared to the global trade in endangered species. The Herpetological Journal 24: 103110.

Hoover C (1998) The U.S. Role in the International live Reptile Trade: Amazon Tree Boas to Zululand Dwarf Chameleons. TRAFFIC North America, Washington.

Ineich I (2006) Les élevages de reptiles et de scorpions au Bénin, Togo et Ghana, plus particulièrement la gestion des quotas d'exportation et la définition des codes 'source' des spécimens exportés. Rapport d'étude réalisée pour le Secrétariat de la CITES. Projet CITES A-251: 1-113.

Jenkins RWG (1998) Management and use of Python regius in Benin and Togo (p. 11). Report prepared for Directorate General XI The Commission of the European Union. 
Jenkins RWG, Jelden D, Webb GJW, Manolis SC (2004) Review of Crocodile Ranching Programs. Conducted for CITES by the CROCODILE SPECIALIST GROUP of IUCN/ SSC. January - April 2004. IUCN-SSC Crocodile Specialist Group. https://www.iucncsg. org/365_docs/attachments/protarea/CSG_-2b73a2ea.pdf

Jensen TJ, Auliya M, Burgess ND, Aust PW, Strand J (2018) Exploring the international trade in African snakes not listed on CITES: Highlighting the role of the internet and social media. Biodiversity and Conservation 28(1): 1-19. https://doi.org/10.1007/s10531-0181632-9

Lambert H, Carder G, D'Cruze N (2019) Given the Cold Shoulder: A review of the scientific literature for evidence of reptile sentience and cognition. Animals (Basel) 9(10): 1-22. https://doi.org/10.3390/ani9100821

Lyons JA, Natusch DJD, Jenkins RWG (2017) A Guide to the Application of CITES Source Codes. CITES, Gland. https://cites.org/sites/default/files/eng/prog/captive_breeding/ESouce $\% 20$ codes\%20booklet\%20-\%20April\%2017.pdf

Newing H (2011) Conducting Research in Conservation: a Social Science Perspective. Routledge, Abingdon. https://doi.org/10.4324/9780203846452

Newton P, Van Thai N, Roberton S, Bell D (2008) Pangolins in peril: Using local hunters' knowledge to conserve elusive species in Vietnam. Endangered Species Research 6: 41-53. https://doi.org/10.3354/esr00127

Potgieter GC, Weise FJ, Wachter B, Melzheimer J, Wiesel I, Stratford K (2017) Comment on Rust et al.: Human-Carnivore Conflict in Namibia Is Not Simply About Black and White. Society \& Natural Resources 30(10): 1299-1303. https://doi.org/10.1080/08941920.20 17.1283077

R Core Team (2017) R: A language and environment for statistical computing. R Foundation for Statistical Computing, Vienna. https://www.R-project.org

Reading CJ, Luiselli LM, Akani GC, Bonnet X, Amori G, Ballouard JM, Filippi E, Naulleau G, Pearson D, Rugiero L (2010) Are snake populations in widespread decline? Biology Letters 6(6): 777-780. https://doi.org/10.1098/rsbl.2010.0373

Regehr EV, Wilson RR, Rode KD, Runge MC, Stern HL (2017) Harvesting wildlife affected by climate change: A modelling and management approach for polar bears. Journal of Applied Ecology 54(5): 1534-1543. https://doi.org/10.1111/1365-2664.12864

Robinson JE, Griffiths RA, St John FAV, Roberts DL (2015) Dynamics of the global trade in live reptiles: shifting trends in production and consequences for sustainability. Biological Conservation 184: 42-50. https://doi.org/10.1016/j.biocon.2014.12.019

Roe D (2008) Trading Nature. A report, with case studies, on the contribution of wildlife trade management to sustainable livelihoods and the Millennium Development Goals. TRAFFIC International and WWF International.

Schai-Braun SC, Kowalczyk C, Klansek E, Hackländer K (2019) Estimating Sustainable Harvest Rates for European Hare (Lepus Europaeus) Populations. Sustainability 11(10): 1-2837. https://doi.org/10.3390/su11102837

Segniagbeto GH, Trape JF, David P, Glitho IA (2011) The snake fauna of Togo: Systematics, distribution and biogeography, with remarks on selected taxonomic problems. Zoosystema 33(3): 325-360. https://doi.org/10.5252/z2011n3a4 
Segniagbeto GH, Petrozzi F, Aïdam A, Luiselli L (2013) Reptiles Traded in the Fetish Market of Lomé, Togo (West Africa). Herpetological Conservation and Biology 8: 400-408.

Segniagbeto GH, Trape JF, Afliademanyo KM, Rödel MO, Ohler A, Dubois A, David P, Meirte D, Glitho IA, Petrozzi F, Luiselli L (2015) Checklist of the lizards of Togo (West Africa), with comments on systematics, distribution, ecology, and conservation. Zoosystema 37(2): 381-402. https://doi.org/10.5252/z2015n2a7

Tensen L (2016) Under what circumstances can wildlife farming benefit species conservation? Global Ecology and Conservation 6: 286-298. https://doi.org/10.1016/j.gecco.2016.03.007

Toudonou CAS (2015) Ball python (Python regius). Species trade and conservation. Snake trade and conservation management (Serpentes spp.). An assessment of the impact of the pet trade on five CITES-Appendix II case studies PYTHON REGIUS. AC28 Inf. 4. https:// cites.org/sites/default/files/eng/com/ac/28/Inf/E-AC28-Inf-04.pdf

UNEP (2019) The Species+ Website. Nairobi, Kenya. Compiled by UNEP-WCMC, Cambridge. www.speciesplus.net. [Accessed: 07/01/2019]

UNEP-WCMC (2005) Benin and Togo - A review of selected species in trade. SRG 35/4/2/1. Prepared for the European Commission Directorate General E - Environment ENV E.3 - Development and environment. United Nations Environment Programme World Conservation Monitoring Centre, Cambridge, 165 pp.

UNEP-WCMC (2014) Review of Python regius from Togo (source R). UNEP-WCMC, Cambridge, 13 pp. http://ec.europa.eu/environment/cites/pdf/reports/SRG\%2068_7\%20Review\%20of\%20Python\%20regius\%20from\%20Togo\%20_public_.pdf

World Bank (2019) Togo. https://data.worldbank.org/country/togo

\section{Supplementary material I}

\section{Questionnaire}

Authors: Neil D’Cruze, Lauren A. Harrington, Délagnon Assou, Delphine Ronfot, David W. Macdonald, Gabriel H. Segniagbeto, Mark Auliya

Data type: survey questionnaire form

Copyright notice: This dataset is made available under the Open Database License (http://opendatacommons.org/licenses/odbl/1.0/). The Open Database License $(\mathrm{ODbL})$ is a license agreement intended to allow users to freely share, modify, and use this Dataset while maintaining this same freedom for others, provided that the original source and author(s) are credited.

Link: https://doi.org/10.3897/natureconservation.38.47864.suppl1 